\title{
EXPERIÊNCIAS DE ENSINO-APRENDIZAGEM REMOTO DE INGLÊS NA LICENCIATURA EM LETRAS/INGLÊS DURANTE A PANDEMIA DE COVID-19: MULTILETRAMENTOS DIGITAIS E INTERSECCIONALIDADE
}

\author{
Fábio Alexandre Silva Bezerra ${ }^{1^{*}}$ \\ ${ }^{1}$ Universidade Federal da Paraíba, João Pessoa, PB, Brasil
}

\begin{abstract}
Resumo
A pandemia de COVID-19 tem evidenciado ainda mais a relevância do uso de recursos digitais, agora especialmente para o estudo e/ou trabalho remoto em contexto de isolamento social. Este artigo discute o ensinoaprendizagem remoto de inglês como L2 na licenciatura em Letras/ Inglês da UFPB, destacando questões linguísticas e temáticas essenciais para a formação docente. Enfatizando metodologias ativas (MORAN, 2018) para a instrução baseada em conteúdo (GRABE; STOLLER, 1997; STRYKER; LEAVER, 1997) na abordagem dos multiletramentos (COPE; KALANTZIS, 2015), do ensino remoto emergencial (HODGES et al., 2020) e da interseccionalidade (AKOTIRENE, 2019; COLLINS; BILGE, 2016), a experiência ora relatada assinala a importância da proatividade dos/as alunos/as, da flexibilidade do/a professor/a, da escolha dos temas-geradores e da adequação dos textos-base para o alcance de bons resultados.

Palavras-chave: Ensino-Aprendizagem Remoto; Inglês como L2; Recursos

Digitais; Licenciatura; Pandemia de COVID-19
\end{abstract}

\section{REMOTE ENGLISH TEACHING-LEARNING EXPERIENCES IN THE TEACHING DEGREE IN ENGLISH DURING THE COVID-19 PANDEMIC: DIGITAL MULTILITERACIES AND INTERSECTIONALITY}

\section{Abstract}

The COVID-19 pandemic has further highlighted the relevance of the use of digital resources, now especially for remote study and/or work in

\footnotetext{
* Doutor em Língua Inglesa e Linguística Aplicada pela Universidade Federal de Santa Catarina. Ph.D. em Linguística pela University of Sydney. Professor Associado do Departamento de Letras Estrangeiras Modernas e do Programa de Pós-Graduação em Linguística da Universidade Federal da Paraíba, onde colidera o GEPLAM - Grupo de Estudos e Pesquisa em Linguística Sistêmico-Funcional, Análise Crítica do Discurso e Multimodalidade/Multiletramentos (UFPB/CNPq). Entre seus interesses de pesquisa, destacam-se os estudos identitários em perspectivas transviada e interseccional, os estudos descoloniais, a análise crítica do discurso multimodal, os multiletramentos e a formação docente. ORCID: https://orcid.org/0000-0002-3383-0188. E-mail: fabes10@yahoo.com.br.
} 
the context of social isolation. This paper discusses the remote teachinglearning of English as L2 in the teaching degree in English at UFPB, highlighting essential linguistic and thematic issues for teacher education. Emphasizing active methodologies (MORAN, 2018) for content-based instruction (GRABE; STOLLER, 1997; STRYKER; LEAVER, 1997) to approach multiliteracies (COPE; KALANTZIS, 2015), emergency remote education (HODGES et al., 2020) and intersectionality (AKOTIRENE, 2019; COLLINS; BILGE, 2016), the experience reported here highlights the importance of student proactivity, teacher flexibility, the choice of the themes and the adequacy of the core texts for achieving good results.

Keywords: Remote Teaching-Learning; English as L2; Digital Resources; Teaching Degree; COVID-19 Pandemic 


\section{Introdução}

Ao pensarmos sobre a sociedade contemporânea e as demandas que produz em tempos da desigual relação entre a proliferação de tecnologias digitais de informação e comunicação (TDIC) e o acesso da população mundial aos frutos das relações econômicas, políticas e sociais produzidos pela globalização, somos instados a considerar como esse desequilíbrio impacta, de maneira direta, os contextos educacionais e seus processos de ensino-aprendizagem. Não acredito, contudo, ser possível falarmos de apenas uma globalização, como noção monolítica. Ao contrário, devemos considerar diferentes processos de globalização (GIDDENS, 2000; SANTOS, 2000) pelos quais diferentes países, populações, comunidades, grupos sociais, e indivíduos têm experiências também particulares, considerando-se, para além das profundas reorganizações sociais em termos de tempo e espaço, importantes marcadores sociais da diferença, tais como raça, classe, gênero, sexualidade, geração, e corporeidades, em relações interseccionais (AKOTIRENE, 2019; COLLINS; BILGE, 2016) produtoras de realidades específicas.

Nessas circunstâncias, professores/as são cada vez mais exigidos/as quanto ao atendimento das necessidades de alunos/as, de mães e pais, de empregadores/ as, enfrentando grandes incertezas ao mesmo tempo em que também se veem despendendo grandes esforços para se (re)qualificar e se (re)adaptar a situações e exigências que podem ser opressivas em diversos âmbitos: profissionais, familiares, sociais, emocionais, mentais, e espirituais.

Tratando mais especificamente do ensino-aprendizagem de línguas estrangeiras no contexto brasileiro, algumas pesquisas têm demonstrado a relevância do uso de TDIC para o incremento da qualidade tanto do desenho das atividades de sala de aula, quanto das oportunidades para desenvolvimento linguístico para além dos muros da escola/universidade. Dentre os temas abordados, podemos citar a mediação cultural no ensino de alemão (PEREIRA, 2018), o ensino híbrido na formação em línguas estrangeiras (MAYRINK; ALBUQUERQUE-COSTA, 2017), o planejamento e a implementação de curso on-line no estágio curricular (GIMENEZ; RAMOS, 2014), a utilização de softwares para o ensino de inglês como L2 na sala de aula invertida (RODRIGUES; MUENCHOW; RIBAS, 2017), a produção de textos nas aulas de espanhol (DACOLTIVO; CASTELA, 2018), a formação de professores/as de línguas (SABOTA; ALMEIDA FILHO, 2017), e o uso de fóruns de discussão para a formação inicial de professores/as de inglês (ANJOS-SANTOS, 2014).

Diante dos desafios particulares impostos pela situação crítica de saúde pública causada pela pandemia de COVID-19, os sistemas de ensino, tanto da Educação Básica quanto do Ensino Superior, têm sido chamados a atender demandas que se apresentam de maneira emergencial e marcadamente inédita no contexto planetário. Dentre essas demandas, podemos destacar a viabilização de experiências de ensino-aprendizagem remoto, o desenvolvimento e/ou adaptação de TDIC para atender às necessidades de rearranjos das relações 
entre professores/as e alunos/as, a (desen)formação docente (PARAQUETT; BEZERRA, 2021) necessária para que seu trabalho seja desenvolvido em meio a sérios desafios particulares e coletivos; além da familiarização com recursos digitais que possam ser úteis para o ensino-aprendizagem em âmbitos específicos.

Nesse contexto, este artigo apresenta resultados de pesquisa que surgiu a partir de um questionamento principal, qual seja: Como as experiências de ensino-aprendizagem de língua inglesa como L2 têm sido impactadas pelo ensino remoto no âmbito da formação docente inicial na licenciatura em Letras/Inglês da Universidade Federal da Paraíba (UFPB) durante a pandemia de COVID-19? A partir dessa pergunta mais ampla, alguns outros questionamentos mais pontuais se delinearam: 1) Qual o impacto da utilização do SIGAA ${ }^{1}$ e da Plataforma Zoom ${ }^{2}$ na motivação dos/as alunos/as para manter efetiva prática da língua inglesa durante a disciplina?; 2) Qual o impacto do uso de metodologias ativas ${ }^{3}$ na condução da disciplina para o engajamento dos/ as alunos/as nas atividades propostas?; 3) Qual o impacto do estado mental/ emocional dos/as alunos/as em sua participação e no seu desempenho durante as atividades propostas na disciplina?

Com base nessas perguntas, foram definidos os seguintes objetivos de pesquisa. Com o objetivo geral de demonstrar o impacto do ensino remoto na aprendizagem de língua inglesa como L2 na licenciatura em Letras/Inglês da UFPB, esta pesquisa se desenvolve orientada pelos objetivos específicos a seguir: 1) avaliar o impacto da utilização do SIGAA e da Plataforma Zoom na motivação dos/as alunos/as para praticar a língua inglesa durante a disciplina; 2) discutir a relevância do uso de metodologias ativas durante a disciplina com vistas ao engajamento dos/as alunos/ as; 3) ponderar em que medida o estado mental/emocional dos/as alunos/as influenciou sua participação e seu desempenho nas atividades propostas.

Visando a contribuir para uma melhor compreensão sobre a configuração dessas novas demandas, sobre as novas habilidades que são esperadas de professores/as e alunos/as, sobre o que se pode esperar no tocante a resultados de aprendizagem nesse contexto de ensino remoto, bem como sobre a maneira como os cursos de formação de professores/as podem se (re)alinhar a essas novas exigências para possibilitar e estimular experiências de ensinoaprendizagem que sejam ao mesmo tempo eficientes, compassivas, criativas, teoricamente embasadas, e adequadas metodologicamente, apresento, a seguir, os procedimentos metodológicos seguidos nesta investigação.

\section{Procedimentos metodológicos}

Diante do fato de que o semestre letivo ocorreria de modo remoto, podendo ser viabilizado, dentre outras possibilidades, pelo uso dos recursos disponíveis no SIGAA e de alguma plataforma de videoconferência, as experiências de ensinoaprendizagem-uso remoto de língua inglesa, na disciplina de código 1404220, em nível avançado, conduzido no período de 08/09/2020 a 16/12/2020, da licenciatura em Letras/Inglês da UFPB, foram organizadas da seguinte maneira, a partir das 
orientações institucionais abaixo. Logo após, são dados outros detalhamentos sobre o desenho desta pesquisa.

Art. $7^{\circ}$ A realização do Período Suplementar dar-se-á por meio de disponibilização, pelo docente, de material didático digital que deverá estar acessível durante todo este período.

$\$ 1^{\circ}$ As plataformas preferenciais a serem utilizadas pelo docente para gestão das atividades acadêmicas serão a Turma Virtual do SIGAA e o Moodle Classes, disponibilizadas pela UFPB, devendo o registro de frequência e as notas dos discentes ser realizado no SIGAA.

$\$ 2^{\circ}$ Fica autorizada a utilização de outras plataformas educacionais digitais e virtuais e de tecnologias da informação e comunicação (Google Classroom, Microsoft Teams, Google Meet, Zoom, Jitsi Meet, Canvas, Mídias Sociais, Whatsapp, Facebook, Instagram, E-mail institucional, dentre outras) para a realização do Período Suplementar (UFPB, 2020, p. 4).

Primeiramente, apesar de ser fornecida a possibilidade de uso gratuito da plataforma Google Meet, decidi continuar com a plataforma Zoom, que já vinha utilizando desde que fiz assinatura do serviço para uso no primeiro semestre de 2020 nas aulas da Pós-Graduação em Linguística (PROLING) também da UFPB. Essa decisão se deu por avaliar que esse serviço de webconferência oferece mais recursos de grande relevância para o ensino-aprendizagem-uso de língua estrangeira, como, por exemplo, a possibilidade de dividir os/as alunos/as da turma em pequenos grupos (breakout rooms), facilitando, assim, atividades orais em grupos menores, ou até mesmo em pares e/ou trios.

Apesar de ter sido possível criar turmas no Moodle Classes, optei por utilizar o próprio SIGAA por entender que os/as alunos/as já o conheciam bem, o que nos possibilitaria contar com suas experiências prévias para aplacar um pouco de sua ansiedade em participar deste semestre remoto - além do fato de que o SIGAA oferece os recursos que, como professor da disciplina, avaliei serem suficientes para a condução eficiente do que havia planejado para o curso, tais como a criação de fóruns de discussão, questionários, atividades, enquetes etc.

O semestre foi organizado a partir de sequências de aulas em que foram: 1) discutidos, de modo síncrono, os temas-geradores ${ }^{4}$ escolhidos em consenso com os/as alunos/as no início do semestre a partir de sugestões iniciais abertas do professor - tendo recebido convidados em dois desses três encontros temáticos para acrescentarem às discussões suas experiências práticas com as temáticas; 2) respondidos, de modo assíncrono, fóruns, questionários, atividades e exercícios sobre os textos-base de cada tema-gerador e sobre aspectos léxico-gramaticais que surgiram a partir de suas leituras; e 3) apresentados seminários curtos sobre algum aspecto relevante para o aprofundamento do tema-gerador escolhido pelos/as alunos/as com interações propostas com os/as colegas de classe.

Mais especificamente com vistas à qualificação do compartilhamento dos resultados dessa experiência nesta pesquisa, os/as alunos/as, no final do semestre, depois de terem o resultado final de seu desempenho inserido no SIGAA, responderam, voluntariamente, um questionário ${ }^{5}$ que buscava colher 
informações acerca de suas percepções sobre o desenho, o desenvolvimento e a conclusão do semestre, abrangendo aspectos como escolha dos temas-geradores e dos textos-base, atividades assíncronas, seminários, uso do SIGAA, participação dos/as convidados/as nas discussões, avaliações, dentre outros.

Por fim, destaco que, para o desenvolvimento das discussões dos temasgeradores, bem como a preparação e a apresentação dos seminários, todo o processo foi conduzido e orientado por metodologias ativas ${ }^{6}$, mais especificamente por práticas de sala de aula invertida (flipped classroom), de aprendizagem entre pares (peer learning) nos seminários, e por meio da promoção de discussões de aprofundamento dos temas-geradores. Tais experiências possibilitaram desenvolver o que Kalantzis e Cope (2021) denominam como repertório de prática, e Omotade e Babalola (2015), repertório pedagógico.

Na próxima seção, o SIGAA e o Zoom são apresentados como recursos digitais no contexto de ensino-aprendizagem-uso de inglês como L2. Em seguida, são descritas algumas particularidades e desafios para a manutenção de atividades educacionais apresentados pelo grave momento de saúde pública causado pela pandemia de COVID-19. Por fim, são apresentados os principais resultados desta experiência, com foco nas respostas dos/as alunos/as ao questionário aplicado, para então serem traçadas algumas considerações finais.

\section{SIGAA e Zoom como recursos digitais para o ensino-aprendizagem- uso de inglês como L2}

A utilização de recursos digitais para planejar, desenvolver e avaliar o ensinoaprendizagem-uso de língua inglesa como L2 é essencial quando pensamos no contexto de ampla presença das TDIC em nossa sociedade. Esse caráter de ubiquidade apresenta desafios particulares para sociedades nas quais o acesso a tais recursos é profundamente desigual, como no Brasil, requerendo dos/as profissionais da educação em geral posturas proativas no sentido de contornar limitações que seus locais de trabalho específicos possam impor.

Esse compromisso de contornar dificuldades para garantir, minimamente, o desenvolvimento da competência comunicativa multimodal (BEZERRA, 2019; HEBERLE, 2010; ROYCE, 2007) dos/as alunos/as é revelador das demandas financeiras, emocionais, e sociais que os/as docentes têm que enfrentar diariamente em suas práticas de ensino, especialmente em contextos educacionais onde não há inclusive livros didáticos para todos/as os/as alunos/ as. Estando cientes dessa situação e dessas particularidades, seguimos com o objetivo de desenvolver multiletramentos digitais críticos, visto que se evidencia o aspecto de maior envolvimento dos/as próprios/as alunos/as por meio dessas ações pedagógicas, além das questões de incremento de fatores referentes à aprendizagem em si (BLAKE, 2005; CHAPELLE, 2003), como, por exemplo, fatores afetivos e crenças (MADEIRA, 2008).

Ademais, essa consciência deve vir acompanhada da clareza, até mesmo pela própria natureza do trabalho com multiletramentos (ROJO, 2012), de que não 
é suficiente apenas disponibilizar os recursos digitais para uso pelos/as alunos/ as. É, portanto, indispensável um trabalho docente que promova reflexão sobre aspectos sociais, econômicos, e profissionais, que parecem criar uma conexão quase indelével entre o sucesso individual e a competência desenvolvida ao lidar com tecnologias que estão em perene mudança e atualização.

Diante de tamanhas demandas e inegáveis desafios, assume grande relevância o planejamento por parte dos/as professores/as de quais recursos digitais incluir em suas práticas docentes para atingir objetivos que sejam claros tanto para eles/as quanto para seus/suas alunos/as (THOMAS; REINDERS; WARSCHAUER, 2014; TUMOLO, 2014). Como exemplos de experiências com recursos digitais para o ensino-aprendizagem de inglês como L2, podemos citar o foco na percepção dos docentes (LEANDRO; WEISSHEIMER, 2019; SILVA; MARIANO; FINARDI, 2018), o desenvolvimento da autonomia dos/as alunos/as no contexto de sala de aula invertida (OFUGI; FIGUEREDO, 2017), o trabalho com produção oral da língua inglesa por meio de podcasts (REIS, 2017), e a atenção à promoção de consciência crítica intercultural por meio de memes na internet (PIRES; MICHELS, 2017).

É nesse contexto de pesquisas mais amplo que o presente estudo descreve os recursos digitais utilizados na experiência ora relatada. Do SIGAA (Fig. 1), destaco os recursos que ele apresenta para o ensino-aprendizagem-uso de inglês como L2 (fóruns, atividades, questionários, mensagens, vídeos, textos etc.).

Figura 1: Visão panorâmica da tela de início da turma virtual no SIGAA

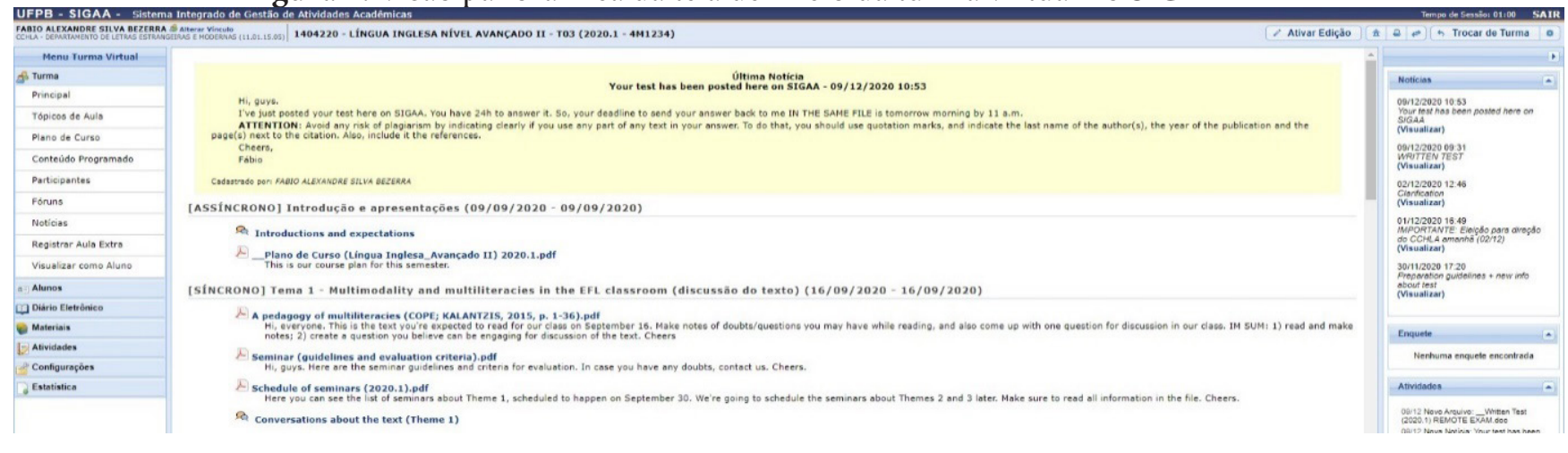

Fonte: Registro de tela (printscreen) e recorte feito pelo autor (2021)

A título de exemplo, os fóruns (Fig. 2) foram muito importantes para manter e fortalecer o engajamento dos/as alunos/as durante os dias de aulas assíncronas, em construção colaborativa (HARASIM, 2012), para aprofundar questões discutidas sobre os textos-base utilizados para tratar dos temas-geradores (descritos na seção sobre a experiência na UFPB), e para abordar questões linguísticas deles decorrentes (BIONDO, 2017; CASSANY, 2012). 
Figura 2: Lista de fóruns criados para participação assíncrona na turma virtual no SIGAA

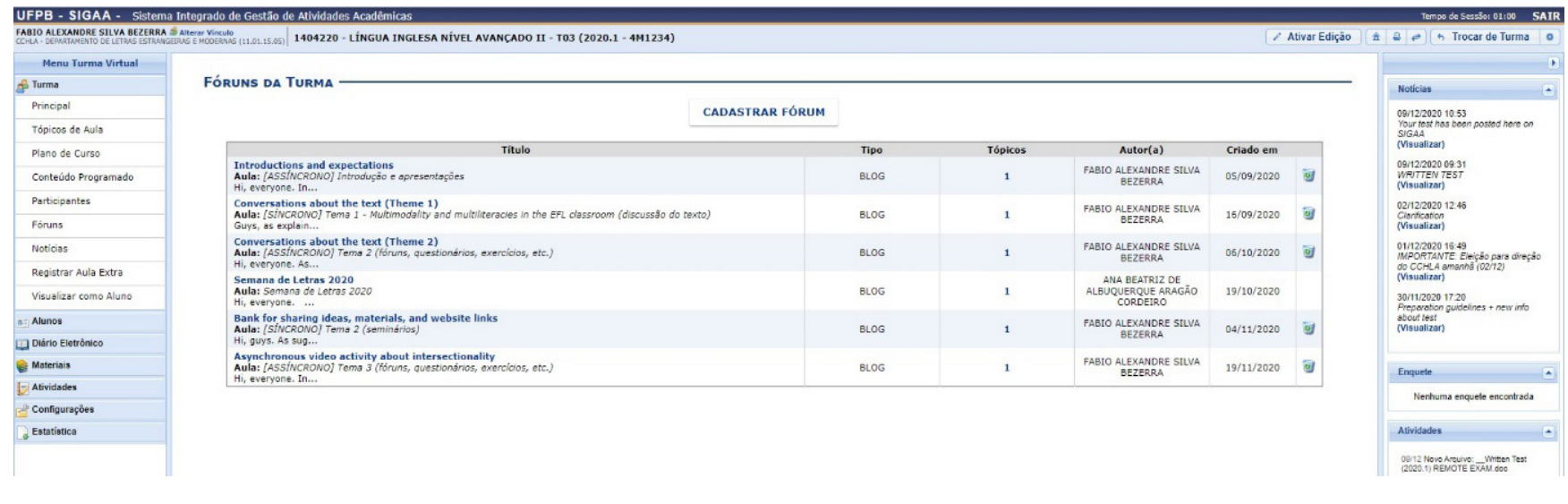

Fonte: Registro de tela (printscreen) e recorte feito pelo autor

Como plataforma de webconferência, o Zoom (Fig. 3), aqui classificado como sistema organizador de recursos digitais, tem se mostrado muito valioso para a qualidade do trabalho de ensino-aprendizagem-uso de inglês como L2 no ensino remoto, destacando, em especial, sua contribuição para o estímulo e para a manutenção da qualidade das interações possíveis em modelo de comunicação não presencial (HAMPEL; STICKLER, 2012). Dele, listo algumas funcionalidades que têm sido úteis para a condução de aulas de inglês como L2, e de prática da língua: quadro branco, chat, vídeo e áudio, breakout rooms, reações por meio de emojis, compartilhamento de arquivos etc.

Dessas, destaco, como já mencionado, em especial a possibilidade de uso de breakout rooms para trabalhos em grupos, e o chat para estímulo da habilidade de escrita na língua estrangeira - onde também há a possibilidade de compartilhar arquivos com a turma que tenham sido mencionados na aula. Esse compartilhamento, contudo, em minha experiência, deve antes ser autorizado pelo/a professor/a por meio de aviso do/a aluno/a, caso contrário o chat pode ficar muito poluído, e também podem ser tomadas direções nas interações que não tenham relação alguma com a aula acontecendo no momento.

Por fim, apesar de ter optado por não utilizar essa funcionalidade, a aula pode ser gravada pelo/a professor/a para posterior compartilhamento com os/as alunos/as. Isso deve, obviamente, ser combinado de maneira consensual com a turma. Também considero importante conversar com a turma, na primeira aula, para informar sobre a necessidade de autorização, em cada situação específica, para que façam registro de tela (printscreen) para que não incorram no risco de infringir direitos autorais ${ }^{7}$, por exemplo, do/a professor/a. 
Figura 3: Visão geral da minha tela de início em uma sala de webconferência do Zoom

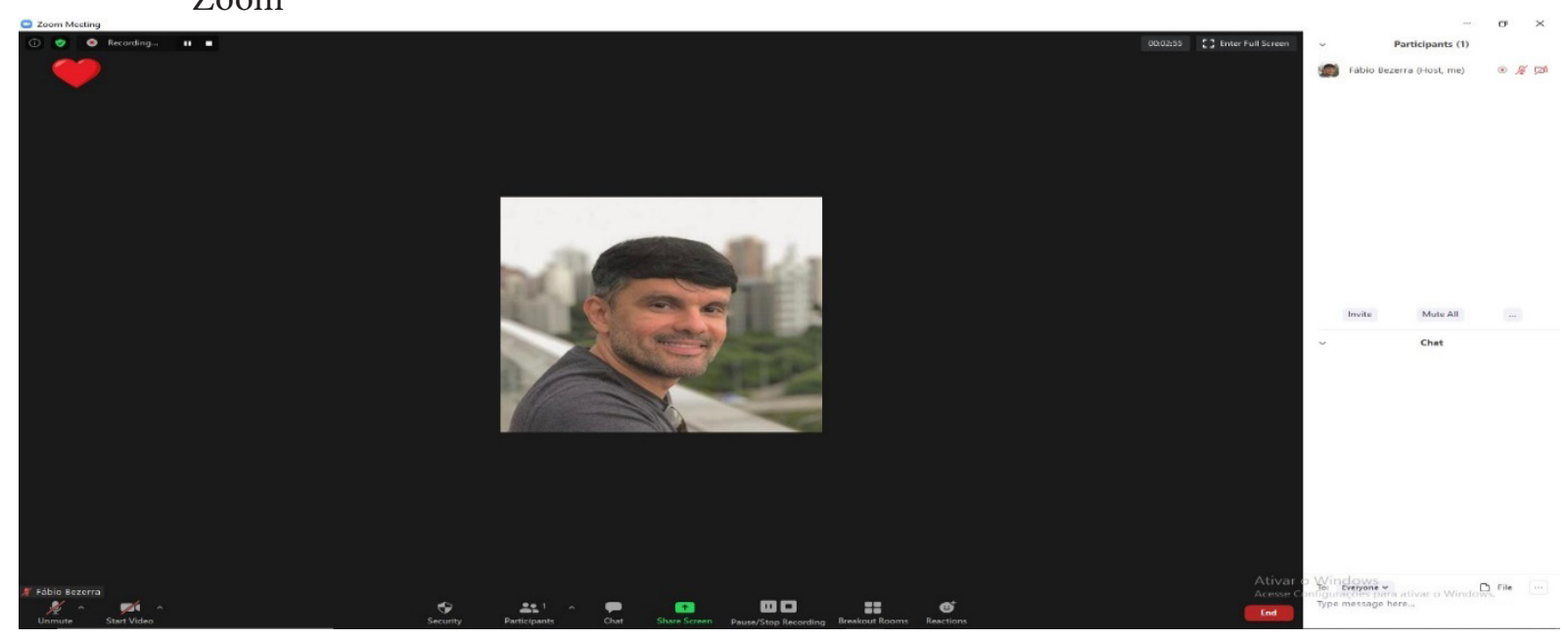

Fonte: Registro de tela (printscreen) feito pelo autor (2021)

Para além dos recursos disponibilizados tanto pelo SIGAA quanto pelo Zoom, os/as alunos/as também puderam explorar, de maneira autônoma, questões da língua inglesa por meio dos seguintes sites/apps, sugeridos por mim, que têm se mostrado úteis, ao longo de minha prática docente, para o ensino-aprendizagem-uso de inglês como L2: Duolingo, MindMeister, InfoEscola, Slidesgo, Smore, TED-Ed, dentre outros. Também foram sugeridos blogs com dicas sobre vocabulário, gramática, prática das quatro habilidades (alguns de maneira integrada), dicas de planos de aula etc., tais como: EnglishAct, TodaMatéria, BBC Learning English, Grammar Girl, ESL Café, BusyTeacher, Learn English, e Randall's Cyber ESL Listening Lab.

\section{Ensino-aprendizagem remoto durante a pandemia de COVID-19: particularidades e desafios}

Acredito ser importante descrever, de maneira breve, com base em minha experiência particular, o contexto desafiador, nos âmbitos social, institucional, profissional e pessoal, no qual essas atividades ora descritas e discutidas se desenvolveram. Considerando a evidente impossibilidade de manter aulas na modalidade presencial, diferentes órgãos públicos publicaram dispositivos legais que pudessem regular a continuidade, mesmo que de forma restrita, das atividades educacionais.

Primeiramente, no âmbito de diversas atividades, o Ministério da Saúde emitiu a Portaria no 188/GM/MS/2020, que declarou Emergência em Saúde Pública de Importância Nacional (ESPIN), sendo seguida pela Lei no 13.979/2020, que determinou medidas específicas para o enfrentamento da COVID-19. Diante dessa grave situação de saúde pública global, a UFPB regulamentou, de maneira emergencial, o trabalho remoto por meio da Portaria n ${ }^{\circ} 231 /$ GR/REITORIA/UFPB. Logo após, o Ministério da Educação autorizou, também de maneira emergencial, o ensino de forma remota no ensino superior por meio da Portaria MEC n 544. 
Diante dessas regulamentações, foi reorganizado o calendário escolar por meio do Parecer CNE/CP n 5/2020, sendo seguido, na UFPB, como já mencionado, pela Resolução no 19/2020, de 06 de agosto de 2020, do Conselho de Ensino, Pesquisa e Extensão (CONSEPE), que trata da "regulamentação de oferta de componentes curriculares para a graduação em um Período Suplementar, [...] com início em 08 de setembro e término em 16 de dezembro de 2020" (UFPB, 2020, p. 1).

Tendo sido, então, determinado o isolamento social e instaurada a modalidade de ensino remoto na UFPB, considerei necessário entender mais sobre esse modelo, visto que se difere tanto do ensino a distância, quanto do ensino online $^{8}$. Como era algo muito recente, minha experiência com ensino remoto emergencial (ERE) foi fundamentada basicamente no estudo de Hodges et al. (2020), tendo selecionado apenas algumas questões para acrescentar à discussão que aqui proponho, em especial no tocante ao tempo de preparação, ao tempo de familiarização, à necessidade de avaliação institucional, e, finalmente, sobre rupturas, estabelecimento de prioridades e ampliação da flexibilidade (docente, discente e institucional) que devem ocorrer inevitavelmente durante esse processo.

Hodges et al. (2020, p. 6, minha tradução) ${ }^{9}$ definem ERE como "mudança temporária de entrega de instrução para um modo alternativo devido a circunstâncias de crise". O tempo de preparação é algo determinante também para caracterizar essa modalidade, a partir de seu caráter de imprevisibilidade, ao contrário da educação a distância, por exemplo, que costuma ter, em média, de seis a nove meses de preparação para o início das aulas - podendo, a depender da complexidade dos cursos oferecidos, ultrapassar esses nove meses. Outra característica complicadora do ERE é que ele demanda muito mais tempo, justamente por seu caráter emergencial (curta preparação), para que os/as profissionais envolvidos/as, especialmente os/as docentes, se familiarizem com sua dinâmica.

Em média, o/a docente estará acostumado a lecionar um componente curricular no ERE apenas na segunda ou terceira vez que o oferta, a depender dos variáveis níveis de expertise - o que acaba ocasionando, frequentemente, implementações subótimas, pois são levadas a cabo da melhor maneira possível dentro do curtíssimo espaço de tempo disponibilizado para tanto. Outra questão importante a se considerar é que, necessariamente, haverá rupturas com hábitos estabelecidos, pois as rotinas às quais estávamos acostumados/as simplesmente não têm como se manter inalteradas em meio a uma pandemia. Essas rupturas acontecem tanto no contexto educacional/institucional quanto também nas relações nos âmbitos pessoal, familiar, e coletivo - sendo necessário, frente a tal situação, exercitar nossa habilidade de empatia e nossa flexibilidade em face de limitações nossas e de nossos/as alunos/as no tocante, por exemplo, a prazos, complexidade de avaliações, escolha de temas a serem tratados em sala de aula etc.

Por fim, especialmente por já ter atuado na educação a distância, entendo que a confusão que é feita entre ensino-aprendizagem on-line, a distância e remoto emergencial, que vai além de questões meramente terminológicas, pode ter repercussões talvez ainda não consideradas, a saber: o uso político do 
termo "aprendizagem on-line", utilizando-se, de má fé, de uma visão leiga de que essa modalidade é totalmente ineficiente, associando-a àquilo que seria, na verdade, ERE a fim de fortalecer discurso neoliberal de privatização de universidades públicas no nosso país. Chamo a atenção para esse fato, sobre o qual não acredito que podemos ter atitude cética, especialmente considerandose os seguidos ataques às universidades e aos/às servidores/as públicos/as que a atual administração nacional do Poder Executivo sequer faz questão de mascarar em nossa história recente (MARTINS, 2019). A fim de ampliar as chances de experiências positivas com ERE durante a pandemia, também acredito ser indispensável uma avaliação institucional sobre as ações que estão sendo tomadas, sendo uma das possibilidades o modelo CIPP, baseado na relação contexto input - processo - produto (HODGES et al., 2020).

Para além da pandemia, também é importante que as universidades regulamentem o ERE a fim de que faça parte de sua estratégia institucional em outras possíveis situações futuras que requeiram atitudes emergenciais no contexto educacional, criando, por exemplo, um "programa de desenvolvimento profissional para a equipe envolvida na missão de instrução de faculdades e universidades" (HODGES et al., p. 11, minha tradução) ${ }^{10}$.

Multiletramentos, ensino-aprendizagem remoto e interseccionalidade: uma experiência na licenciatura em Letras/Inglês da UFPB

Agora, descrevo e avalio o percurso e os resultados da disciplina de língua inglesa ministrada no período suplementar 2020.1 na modalidade de ensinoaprendizagem remoto. Para tanto, faço algumas considerações prévias sobre metodologias ativas nessa experiência, para então qualificar a discussão ao trazer também as vozes dos/as alunos/as por meio de respostas ao questionário aplicado no final do semestre.

Como já é largamente conhecido no âmbito dos estudos da linguagem, especialmente na área de estudos de aquisição de língua (estrangeira), a utilização de metodologias ativas não é algo novo (LARSEN-FREEMAN, 2000). Temos uma larga tradição, especialmente a partir do advento das abordagens comunicativas (RICHARDS; RODGERS, 2001), de lançar mão de técnicas e de procedimentos que estimulem o envolvimento e a participação proativa dos/as alunos/as no processo de ensino-aprendizagem, compreendendo-os/as como coparticipes na construção do conhecimento, não apenas em atividades de discussões temáticas, mas também no próprio trabalho contextualizado com o código linguístico (CULLEN, 2008; NUNAN, 1998).

Éinteressante, contudo, saber que essa compreensão do lugar de protagonismo que os/as alunos/as devem ter no contexto de ensino-aprendizagem remonta do final do século XIX, ao vermos que, em seu livro Palestras aos professores sobre Psicologia e aos estudantes sobre alguns ideais de vida, William James (1899) afirma que "[seu] principal desejo tem sido fazer com que [os/as professores/ as] concebam e, se possível, reproduzam solidariamente em sua imaginação, a 
vida mental de seu/sua aluno/a como uma espécie de unidade ativa que ele/a próprio/a assim percebe" (JAMES, 1899, p. iv, meu grifo, minha tradução) ${ }^{11}$.

Também enfatizando o protagonismo da ação dos/as alunos/as nos processos de ensino-aprendizagem, John Dewey (1938) destaca, contudo, que a educação progressista em si não resolve problemas; ao contrário, são apresentados novos problemas, que precisam ser tratados a partir de uma nova perspectiva filosófica sobre a experiência. Vemos, assim, que as discussões sobre educação não tradicional, sobre o lugar central dos/as alunos/as, sobre a importância do contexto, dos conhecimentos prévios e da autonomia nos processos de ensino-aprendizagem, que dão suporte para práticas com metodologias ativas, não são recentes (MORAN, 2016).

Seguindo a orientação de Hodges et al. (2000) para o ERE, bem como o disposto na Resolução no 19/2020 do CONSEPE (UFPB, 2020), o cronograma da disciplina foi organizado procurando favorecer encontros assíncronos, especialmente levando em consideração a dificuldade de acesso a computadores e à internet de boa qualidade por uma parte considerável dos/as alunos/as de nossa universidade - situação que também se passa em instituições de outras unidades da federação -, sem considerar ainda os diferentes níveis de letramento digital tanto de professores/as quanto de alunos/as (JEWITT, 2008). Em conversa com os/as alunos/as no primeiro encontro síncrono, concluímos que poderíamos, na verdade, manter uma equiparação entre encontros síncronos e assíncronos, algo que ajudou bastante na condução do plano de curso.

Em termos de organização do plano de curso, além de trabalhar com metodologias ativas, também optei, como já mencionado, por trabalhar com três blocos de temas-geradores a partir de textos-base, cuja discussão aconteceu nos encontros síncronos e foi aprofundada por meio de construção colaborativa em fóruns no SIGAA. A partir dessa escolha pela instrução baseada em conteúdo (GRABE; STOLLER, 1997; STRYKER; LEAVER, 1997), com base no princípio metodológico de "ensinar LE por meio de conteúdos disciplinares [...], de modo a fazer uso autêntico da língua como meio, não como fim (TUMOLO, 2015, p. 105), os temas-geradores e os textos-base foram os seguintes: Multimodality and multiliteracies in the EFL classroom (COPE; KALANTZIS, 2015); Remote learning and teaching in the EFL classroom (HODGES et al., 2020); e Intersectionality in the EFL classroom [gender, sexuality, race, ethnicity, class, age, spirituality, and body diversity] (COLLINS; BILGE, 2016).

Ao apresentar, a seguir, os elementos constitutivos de minha experiência com ERE (Fig. 4), devo reconhecer, também, que meus conhecimentos prévios tanto com metodologias ativas (cf. BEZERRA, 2018), como com educação a distância, ampliaram o espectro de ações, de estratégias e de repertório sobre letramentos digitais que me permitiu alcançar resultados satisfatórios, especialmente quando consideramos que a experiência relatada ocorreu durante uma pandemia.

Nessa experiência no semestre 2020.1, percebi que alguns aspectos foram marcantes para o desenvolvimento de posturas adequadas e que conduziram à aprendizagem mais significativa nesse processo, a saber: o estímulo da autonomia dos/as alunos/as a partir de um feedback orientador; o respeito à resistência dos/as 
alunos/as a alguns fatores do plano de curso que poderiam lhes causar demandas excessivas, aumentando, assim, inadvertidamente, seus níveis de estresse e ansiedade; o convite à construção de uma relação de parceria, visto que também os/as professores/as estão passando por uma pandemia, e têm seus limites, suas dificuldades e suas preocupações particulares, que, sem dúvida, podem impactar no processo de ensino-aprendizagem; o compromisso com o próprio aprendizado, levando em consideração seu contexto particular e suas limitações, que deveriam ser compartilhadas com o/a professor/a para fazer adaptações que fossem viáveis; o desenvolvimento de uma postura de pesquisadores/ as, especialmente importante para a apresentação de seus seminários, e para a participação nos fóruns de aprofundamento da discussão dos temas no SIGAA; e, por fim, a valorização da criatividade dos/as alunos/as em, por vezes, procurar cumprir as demandas da disciplina de maneira mais leve e compartilhada com outros/as colegas da turma.

Figura 4: Elementos constitutivos de experiência bem-sucedida com ERE

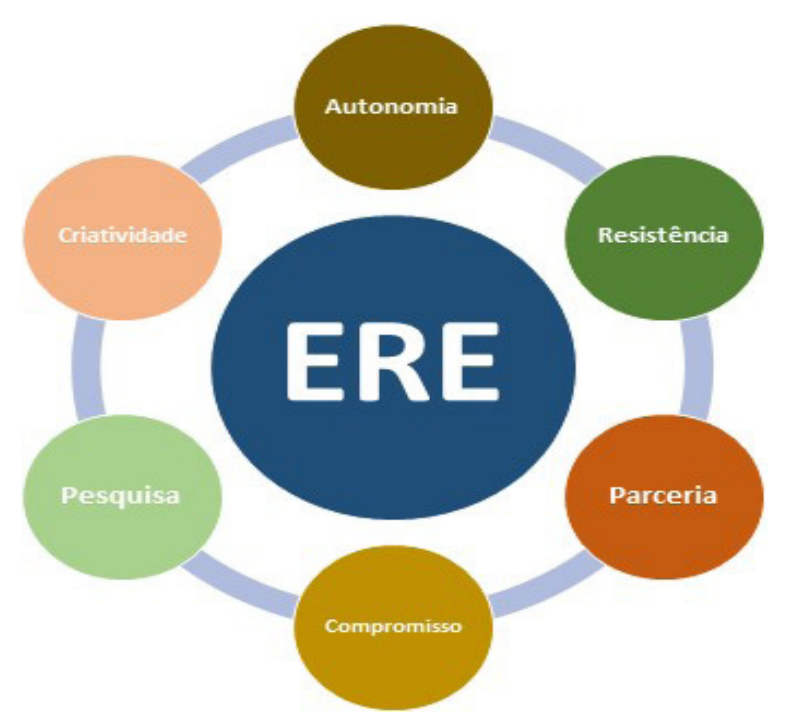

Fonte: $\mathrm{O}$ autor (2021)

Entendendo metodologia, especialmente no contexto de ensino-aprendizagem de línguas (estrangeiras), como o estudo e a utilização de práticas pedagógicas, alinhados a fundamentos teóricos particulares, aplicada por meio de abordagens específicas orientadas por noções explícitas sobre a natureza da linguagem/língua, sempre é necessário escolhermos e estabelecermos processos potencialmente eficientes para a condução da aprendizagem em contextos determinados. Dentre as metodologias ativas disponíveis para o ensino-aprendizagem-uso de inglês como L2, fizemos uso de uma combinação entre sala de aula invertida (flipped classroom), aprendizagem baseada em projetos (apresentações de seminários), discussões em sala de aula sobre os temas-geradores, e aprendizagem entre pares (peer learning), especialmente por meio das participações nos fóruns de aprofundamento sobre os temas discutidos naquele momento. 
Dos/as doze alunos/as que finalizaram o semestre, seis responderam ao questionário para esta pesquisa. Contando, assim, com uma amostragem de metade dos/as alunos/as da turma, acredito ser possível apresentar dados relevantes para a discussão (obviamente não generalizadora) sobre a adequação (ou não) das metodologias, dos tipos de atividades propostas, da escolha dos temas-geradores, dos textos-base sugeridos para fundamentar o início das discussões nos encontros síncronos, do sistema de avaliação e, também, da experiência com ERE de uma forma mais geral.

Informação bastante relevante para o início das considerações acerca da experiência aqui relatada é o fato de que dois terços (2/3) dos/as alunos/as estavam tendo aulas por meio de ERE pela primeira vez na licenciatura (Graf. 1), mesmo ela já tendo sido oferecida, de maneira mais limitada, no primeiro semestre suplementar, em período mais curto, na UFPB. Notem que os/as seis alunos/ as responderam a pergunta sobre avaliação da experiência prévia, quando, na verdade, apenas dois/duas deveriam ter respondido. De qualquer forma, tendo checado as avaliações ${ }^{12}$ feitas pelos/as alunos/as que responderam de maneira afirmativa a pergunta anterior, pude constatar que as notas foram 4 e 5 , ou seja, suas experiências foram positivas. Um/a deles/as, inclusive, acrescentou comentário escrito afirmando que aquela havia sido uma oportunidade de estudar em horários mais flexíveis.

Gráfico 1: (Avaliação da) experiência anterior com ERE
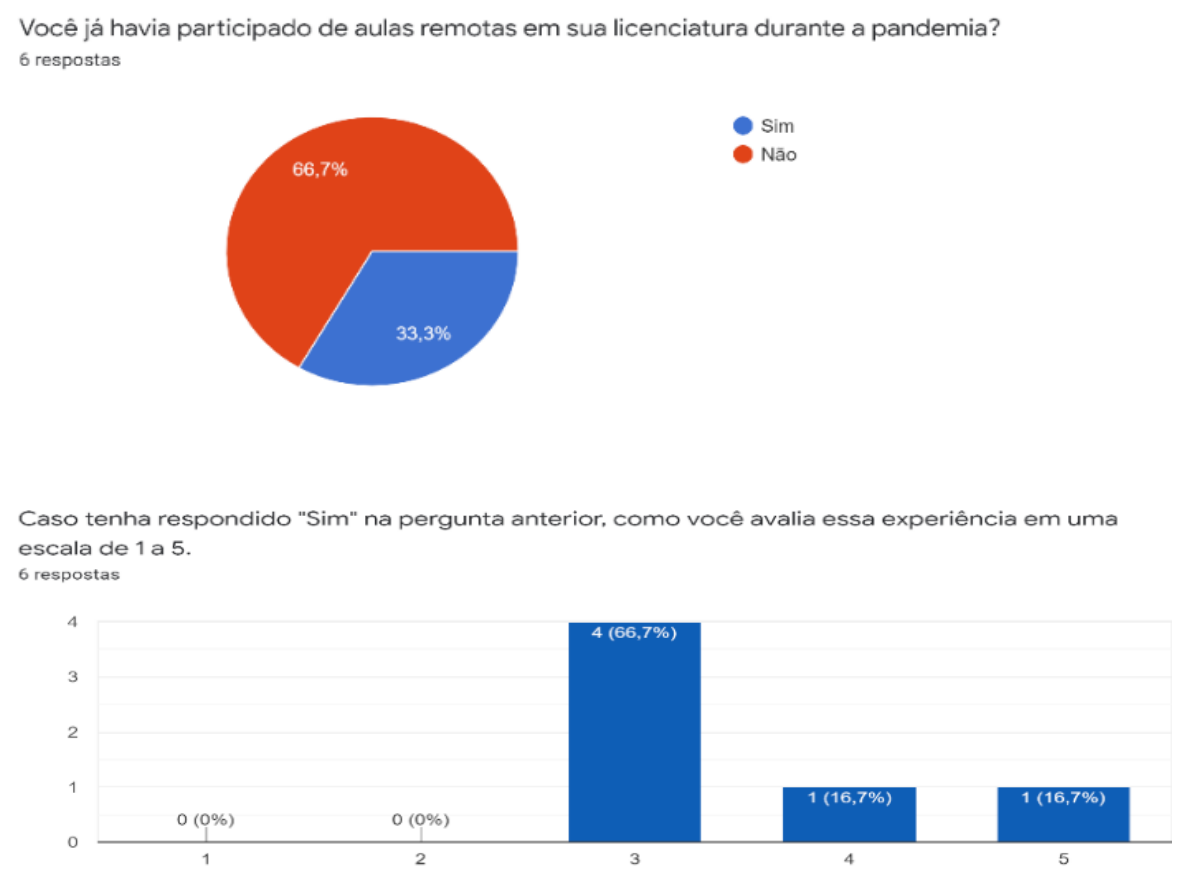

Fonte: Excerto do questionário produzido pelo autor no Google Forms (2021)

Outro fator que considero bastante relevante para avaliarmos a experiência com ERE em 2020.1 é o estado emocional dos/as alunos/as, no início e no fim do semestre letivo. A esse respeito, como acredito ser esperado, especialmente 
em 2020.1, diante dos desafios até então já postos pela pandemia de COVID-19, todos/as atribuíram notas de 1 a 3 a seus estados emocionais (Graf. 2), indicando, assim, evidente desgaste. Dentre os principais motivos para esta situação, estavam ansiedade acumulada, dúvida sobre a qualidade da experiência a ser vivida, experiência anterior negativa com ERE, além de preocupação/desconforto em ter que participar de chamadas de vídeo.

Gráfico 2: Avaliação do estado emocional no início do semestre

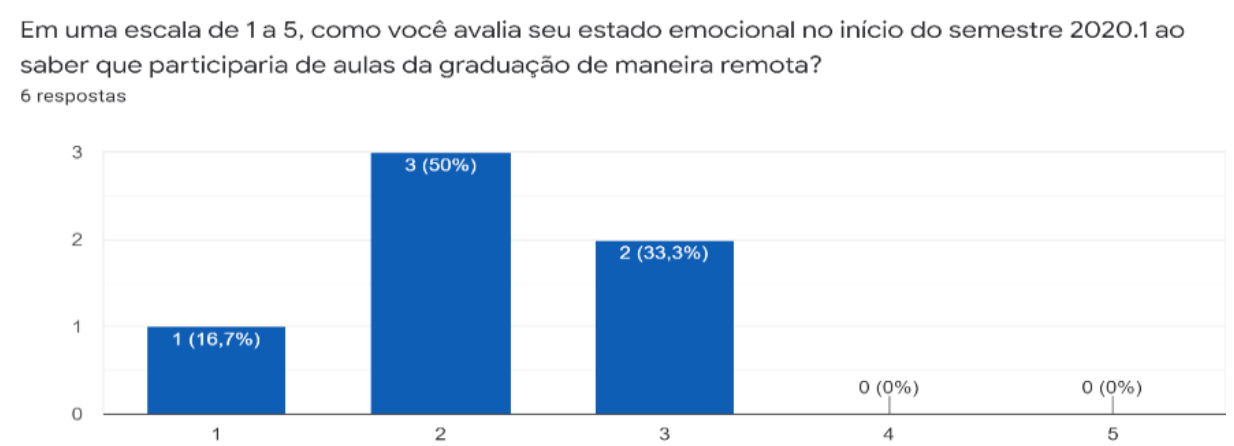

Fonte: Excerto do questionário produzido pelo autor no Google Forms (2021)

Além do estado emocional, também me interessou conhecer a expectativa inicial que tinham em relação à disciplina de língua inglesa que eu lecionaria (Graf. 3). Apesar de um excelente indicativo que a metade deles/as tinha boa expectativa (nota 4), a outra metade, compreensivelmente, estava incerta (nota 3). Os motivos principais apresentados para essa incerteza, ou talvez receio, foram dificuldade adicional por terem que falar na língua estrangeira por meio digital, e o fato de que não sabiam como seria cursar disciplinas durante a pandemia, momento em que todos/as enfrentam desafios muito particulares, variáveis de acordo com marcadores sociais da diferença como classe, gênero, idade, e profissão.

Gráfico 3: Expectativa inicial sobre a disciplina

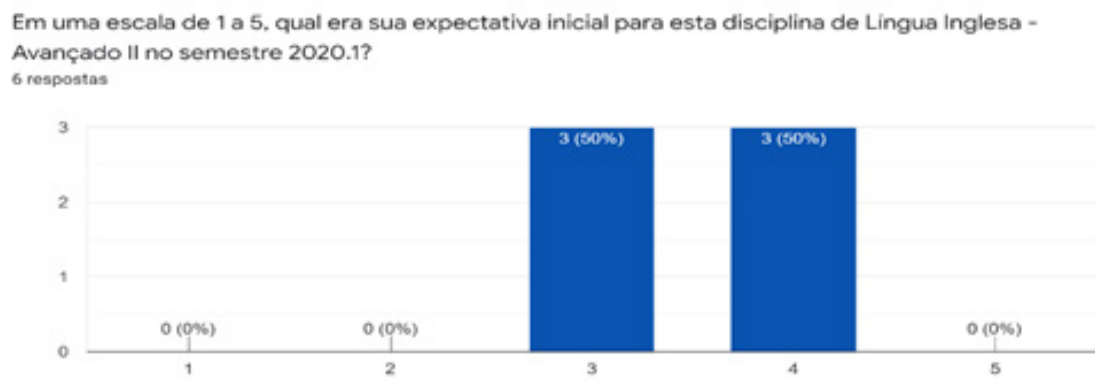

Fonte: Excerto do questionário produzido pelo autor no Google Forms (2021) 
Foi interessante perceber que a mesma distribuição de notas aconteceu quando perguntados/as sobre o desempenho geral na disciplina: metade avaliou seu desempenho como regular (nota 3), e a outra metade como bom (nota 4). Dos motivos para essas avaliações, a maioria afirmou ter feito o seu melhor e ter saído melhor do que esperava, mas também houve comentários no sentido de que a experiência poderia ter sido mais proveitosa se tivesse participado das atividades no SIGAA, mesmo tendo justificado a falta de participação devido à imensa demanda de trabalho que estava enfrentando, a qual também estava ocorrendo on-line. Quanto a essas atividades assíncronas no SIGAA, devo ressaltar que foram consideradas boas (nota 4) pela metade dos/as alunos/as, e muito boas (nota 5) pela outra metade, com destaque positivo para a flexibilidade do professor com relação aos prazos.

Ao comparar o estado emocional no início do semestre e aquele experienciado no final de 2020.1 (Graf. 4), é muito relevante perceber que a avaliação de apenas dois/duas alunos/as foi negativa (notas 1 e 2) - devido a problemas familiares, por exemplo, infecção pelo novo coronavírus -, ao passo que também dois avaliaram como regular (nota 3) e outros dois como muito bom (nota 5). Apesar de não poder, obviamente, afirmar que essa mudança ocorreu unicamente com base na experiência com a disciplina em 2020.1, provavelmente havendo outros fatores que contribuíram para essa melhora, como a pergunta fazia referência específica à disciplina, considero seguro depreender que, pelo menos em parte, houve contribuição positiva de nossas experiências em grupo para esse novo quadro que se apresentou. Essa afirmação pode ser confirmada, por exemplo, por um dos comentários que destacou a tranquilidade e a flexibilidade com que a disciplina foi conduzida como fatores que contribuíram para sua segurança, além de outro comentário que expressava a satisfação em ter conseguido concluir a disciplina, em parte devido ao apoio recebido do professor e dos/as colegas.

Gráfico 4: Avaliação do estado emocional no final do semestre

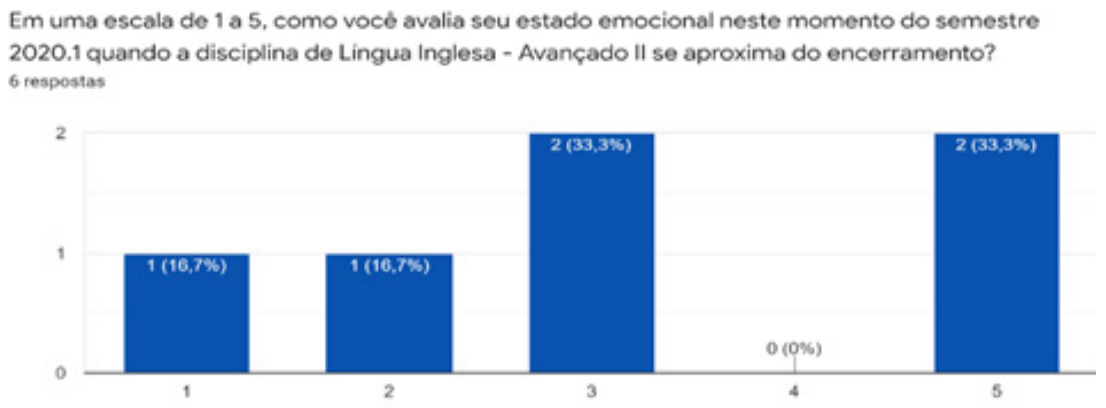

Fonte: Excerto do questionário produzido pelo autor no Google Forms (2021)

Agora, mais especificamente com relação aos temas-geradores e aos textosbase selecionados para leitura (Graf. 5), de acordo com o plano de curso, quase todos/as disseram que o tema 3 (Intersectionality in the EFL classroom) foi o favorito, tendo apenas um/a respondente escolhido o tema 2 (Remote learning 
and teaching in the EFL classroom). Considero esse resultado altamente positivo, especialmente quando consideramos a necessidade de práticas docentes que incluam o aprofundamento do conhecimento e a discussão sobre temas tão relevantes, que impactam, de maneira bastante significativa, a vida de milhões de pessoas em nosso país, a partir de marcadores sociais da diferença particulares, como classe, gênero, sexualidade, corporeidades, idade, espiritualidade etc.

Quanto aos textos selecionados, também houve uma massiva avaliação positiva, com um terço (1/3) dos/as alunos/as avaliando-os como bons (nota 4) e dois terços (2/3) atribuindo-lhes a nota 5 (muito bons), sendo dado destaque para a expertise do professor ${ }^{13}$, a atualidade dos textos, a riqueza das discussões a partir das leituras feitas, bem como seu tamanho adequado (não eram muito extensos ou cansativos). Além da qualidade dos textos, todos/as os/as alunos/ as avaliaram como muito boas (nota 5) a participação do/a convidado/a que tivemos para aprofundar as discussões sobre os temas 2 e 3 , respectivamente, a partir de suas práticas específicas de sala de aula e de pesquisa. Ele, para falar sobre sua experiência com aulas on-line de inglês durante a pandemia no ensino médio, como professor de escola estadual integral de referência em João Pessoa; e ela, mulher paraibana negra, para falar sobre intersecções entre gênero, raça, classe e origem a partir de sua experiência como professora e pesquisadora em universidades estadunidenses.

Gráfico 5: Avaliação dos temas-geradores e dos textos-base selecionados

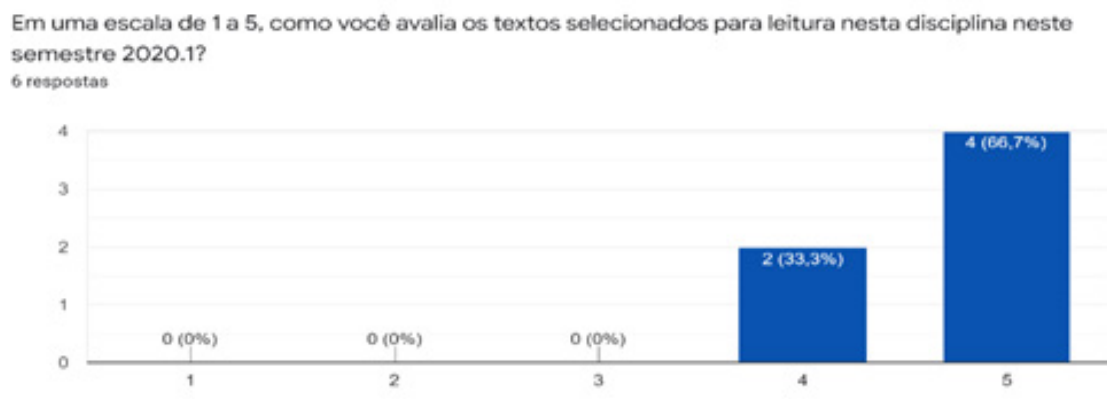

Qual foi seu tema preferido? 6 respostas

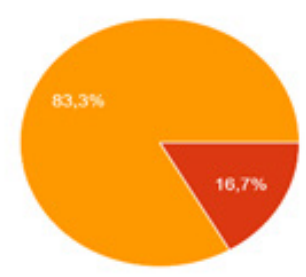

Multimodality and mutcliteracies in the
EFL classroom

Remote learning and teaching in the

EFL classroom

Intersectionality in the EFL classrom 


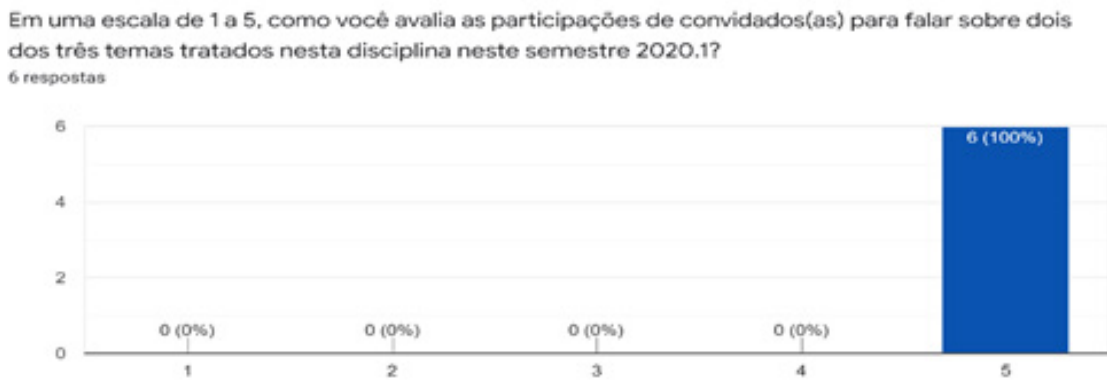

Fonte: Excerto do questionário produzido pelo autor no Google Forms (2021)

Um dos componentes de nossa experiência com esta disciplina em 2020.1 que me causava receio com relação à avaliação dos/as alunos/as, não porque teria que ser positiva, mas porque eu me sentia um pouco ansioso para saber se a obrigatoriedade de apresentar seminários, como uma das notas do semestre, teria causado considerável estresse adicional em um momento em que motivos para ansiedade já eram muitos devido à pandemia.

Apesar de sempre pedir feedback dos/as alunos/as depois de suas apresentações, tendo, inclusive, acompanhado a preparação de suas apresentações, devo dizer que me questionava se eles estariam avaliando de forma positiva essa obrigatoriedade apenas para não me contrariar, visto que havíamos estabelecido uma relação próxima e leve. Tendo aplicado o questionário, constatei que, apesar de a experiência ter sido apenas regular (nota 3) para um terço (1/3) dos/as alunos, ela havia sido boa (nota 4) e muito boa (nota 5) para os outros dois terços (2/3), indicando, dessa maneira, uma avaliação de regular a muito boa (Graf. 6) - resultado muito satisfatório quando pensamos na obrigatoriedade de apresentar seminários, ainda mais na modalidade on-line, em face de tantos desafios já vividos até aquele momento.

Dentre os comentários sobre os seminários, foi mencionado que gostaram do desafio (mesmo que não tenha gostado de seu resultado), que foi uma experiência interessante (mesmo que tenha experienciado nervosismo por ser on-line), que o modelo sugerido pelo professor, por ser simplificado, permitiu-lhes apresentá-lo com maior tranquilidade, especialmente porque os temas já teriam sido discutidos, tanto nas aulas síncronas quanto nos fóruns assíncronos postados no SIGAA.

Gráfico 6: Avaliação da experiência de apresentar seminários

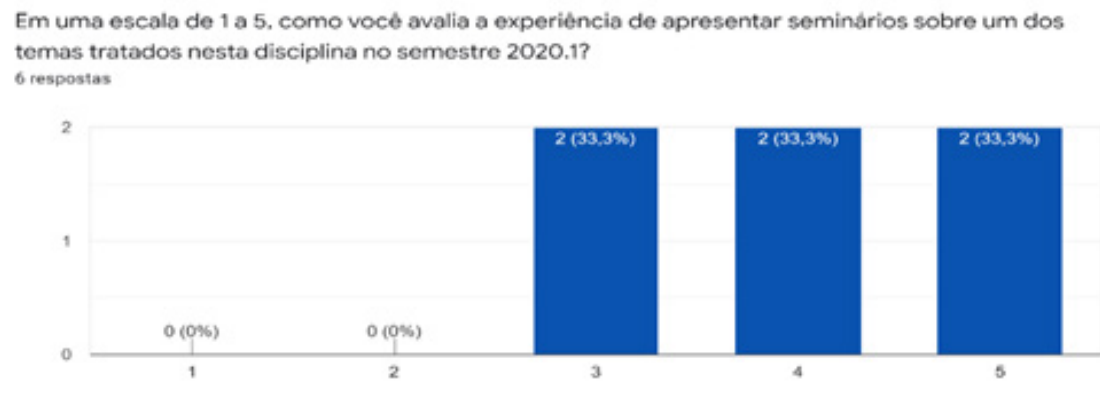

Fonte: Excerto do questionário produzido pelo autor no Google Forms (2021) 
Por fim, tendo em vista a necessidade de obter uma avaliação mais geral a respeito de suas experiências de ensino-aprendizagem em 2020.1 (Graf. 7), enquanto apenas uma pessoa a avaliou como regular (nota 3), por julgar que ainda precisa melhorar no sentido de administrar melhor a experiência com ERE, todas as outras a avaliaram de maneira bastante positiva (notas 4 e 5), assinalando que o semestre havia sido surpreendentemente bom. Também foi interessante o destaque feito, em um dos comentários, para o grande esforço que os/as professores/as estão demonstrando para fazer um bom trabalho, especialmente quando consideramos o cenário pandêmico atual.

Gráfico 7: Avaliação geral da experiência de ensino-aprendizagem em 2020.1

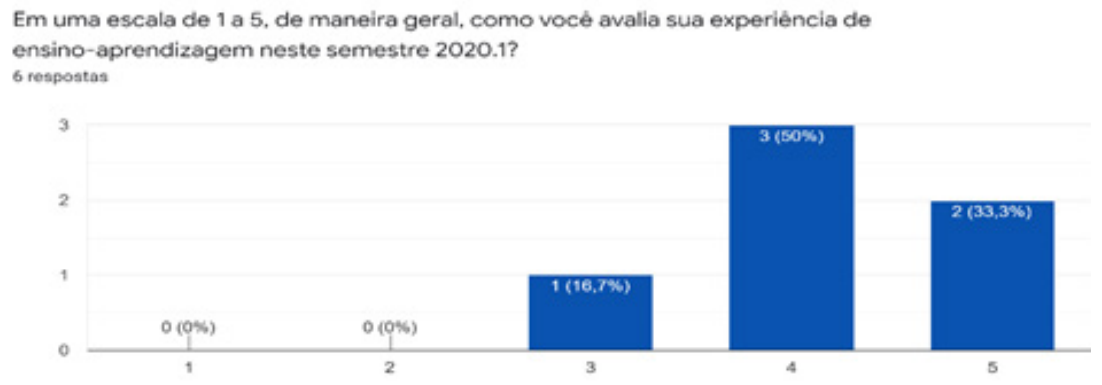

Fonte: Excerto do questionário produzido pelo autor no Google Forms (2021)

Com base nas considerações feitas inicialmente, nos dados aqui apresentados, bem como nas análises das respostas aos questionários, traço algumas considerações finais a seguir ao recuperar as perguntas que originaram esta pesquisa.

\section{Considerações Finais}

Neste artigo, busquei demonstrar como o ensino-aprendizagem de língua inglesa, e de conteúdos temáticos associados, foi impactado pelo fato de que a disciplina ministrada foi conduzida na modalidade de ERE, na licenciatura em Letras/Inglês da Universidade Federal da Paraíba (UFPB) durante a pandemia de COVID-19, dando especial destaque para a utilização de recursos digitais que favorecessem o alcance de resultados satisfatórios.

Quanto ao uso do SIGAA e do Zoom, foi possível constatar um impacto bastante positivo no despertar, no desenvolvimento e na manutenção da motivação dos/as alunos/as tanto para o conhecimento acerca de questões linguísticas quanto para o aprofundamento sobre os temas-geradores. Como demonstrado, os recursos digitais do SIGAA que mais contribuíram nesse sentido foram os fóruns de discussão e o compartilhamento de materiais (textos adicionais, vídeos etc.). O Zoom, por sua vez, como recurso de webconferência, com suas funcionalidades de vídeo/áudio, de separação em grupos menores, 
de conversas escritas no chat, além do quadro branco e das reações por meio de emojis, também foi essencial para que nossas experiências nessa disciplina pudessem ter bom grau de interatividade, requerendo multiletramentos digitais também bastante relevantes.

O trabalho com metodologias ativas demonstrou resultados proveitosos, especialmente no que concerne à visão de coparticipação na construção do conhecimento acerca dos temas-geradores. Para as discussões nos encontros síncronos, os/as alunos/as tinham que ter lido sobre o assunto daquela aula com antecipação, assinalando nos textos-base questões mais significativas, assim como dúvidas e possíveis discordâncias, exemplificando, dessa forma, a prática de sala de aula invertida (flipped classroom).

Dessa maneira, os encontros síncronos foram destinados para o aprofundamento nas temáticas, a partir de suas leituras e de experiências e conhecimentos prévios - explorando, assim, os componentes ${ }^{14}$ da experiência e da conceituação em uma pedagogia dos multiletramentos. Além dessas metodologias, apesar do receio inicial compartilhado, os seminários, como aprendizagem baseada em projetos, foram oportunidades ricas de associação da aprendizagem sobre os temas com atividades específicas de sala de aula, que demandaram dos/as alunos/as a aplicação do conhecimento para a promoção da aprendizagem de seus pares durante as apresentações, momento em que outra metodologia ativa era acionada (peer learning). Por fim, essas metodologias também foram importantes para o desenvolvimento do senso crítico dos/as alunos/as (e, claro, também do professor) sobre as questões postas para análise.

Quanto ao impacto do estado mental/emocional dos/as alunos/as em sua participação e em seu desempenho na disciplina, como já mencionado, no início do semestre, os/as alunos informaram a situação de desgaste provocada pela pandemia, demonstrando ansiedade, dúvidas, receios com ERE, e potencial desconforto com chamadas de vídeo. Além disso, suas expectativas para a disciplina também eram, em geral, incertas, devido à preocupação em ter que falar em inglês em suporte on-line, e também em face dos desafios particulares que já viviam naquele momento em outras esferas de suas vidas, recortadas por fatores interseccionais como classe, idade, gênero e profissão.

A partir de suas respostas ao questionário, foi possível constatar que foram desenvolvendo, ao longo do semestre, uma relação mais saudável com o ensino remoto, sendo culminada, no final de 2020.1, com a percepção compartilhada de que tudo tinha valido a pena, visto que conseguiram concluir a disciplina com bom aproveitamento. Isso não descarta, contudo, eventuais situações de desgaste que persistiram (questões familiares) e/ou foram acrescentadas (infecção pelo novo coronavírus) em associação com demandas dos âmbitos pessoais e profissionais. Como fatores que contribuíram de maneira positiva para a melhora do estado mental/emocional dos/as alunos/as, em comparação ao relatado inicialmente, foram assinalados o apoio dado pelo professor e pelos/as colegas durante o percurso, e também a flexibilidade do professor, especialmente quanto a prazos. 
De modo geral, houve melhora significativa no estado mental/emocional para dois terços (2/3) dos/as alunos/as participantes desta pesquisa. Nesse sentido, a satisfação com os temas-geradores e os textos-base, com o/a convidado/a que contribuiu para o aprofundamento das discussões das temáticas escolhidas, e também com as atividades decorrentes postadas no SIGAA, foi primordial para a evolução nesse aspecto ao longo do semestre.

Mais especificamente quanto aos resultados apresentados nesta pesquisa, o fato de que metade do total de doze alunos/as respondeu o questionário é uma limitação percebida. Ademais, optei por não colher dados diretamente com os/as alunos/as durante o semestre a fim de não criar demandas adicionais, causando, de maneira inadvertida, piora em seu estado mental/emocional por causa de minha pesquisa. No entanto, como espero ter demonstrado, os dados obtidos revelaram questões essenciais a serem consideradas, particularmente nos momentos de preparação dos planos de curso, tais como: escolha compartilhada dos temasgeradores e dos textos-base, envolvimento dos/as alunos/as na coconstrução do conhecimento por meio de metodologias ativas, além da necessidade de parcimônia ao decidir sobre avaliações e de flexibilidade na condução da disciplina, em especial com relação a prazos.

Para investigações futuras, acredito ser muito relevante observarmos como outros recursos digitais, além dos aqui descritos, podem contribuir de maneira positiva para o ensino-aprendizagem-uso de inglês como L2, marcadamente no contexto pandêmico que ainda vivemos. Adicionalmente, a inclusão de dados mais específicos sobre perfis dos/as alunos/as, especialmente quanto a importantes marcadores sociais da diferença, como classe, gênero, idade e profissão, seria importante na triangulação de dados para, quem sabe, tentarmos delinear relações entre as demandas do ERE com desafios particulares vividos por nossos/as alunos/as, como, por exemplo, o próprio acesso a recursos digitais básicos, essenciais nesses contextos.

Apesar da dificuldade que enfrentamos em seguir fazendo pesquisa, e compartilhando resultados por meio de publicações, especialmente em contexto pandêmico, quando estamos passando por desafios nos âmbitos pessoal, profissional, social, mental, emocional e espiritual, fico feliz por estar estabelecendo este contato com potenciais leitores/as. Espero que as informações, os dados e, principalmente, as reflexões aqui apresentados sejam recebidos como apenas uma tentativa de aproximação com questões tão complexas a partir de minha experiência como professor no ensino superior neste país que, atualmente, tem enfrentado sérios problemas sociopolíticos e econômicos.

A nós, caros/as alunos/as, colegas, leitores/as e amigos/as, cabe o exercício efetivo da esperança, da solidariedade e da resistência, pois, como nos lembra Belonísia, personagem inesquecível do lindo e pungente romance Torto Arado, do baiano Itamar Vieira Junior, ao se referir ao povo negro, tem sido "a nossa valência poder se adaptar, poder construir essa irmandade, mesmo sendo alvos da vigilância dos que queiram nos enfraquecer" (VIEIRA JUNIOR, 2018, p. 136). Além das questões de raça, muitos/as de nós também enfrentamos desafios particulares, 
potencializados neste contexto pandêmico, marcados por entrecruzamentos identitários, sociais, econômicos e políticos, que nos posicionam, muitas vezes, em entre-lugares (SANTIAGO, 2000) por vivermos experiências dissidentes nos aspectos de gênero, de sexualidade, de corporeidades, de espiritualidade etc. Sigamos firmes, fortes, (auto)compassivos/as, criativos/as e autênticos/as!

\section{Agradecimentos}

Gostaria de expressar gratidão aos/às alunos/as pela oportunidade de construir coletivamente e compartilhar a experiência relatada neste artigo. Espero que vocês também avaliem que, em tempos tão desafiadores, a coragem demonstrada, o entusiasmo vivido, as preocupações expressadas, as habilidades compartilhadas, o apoio dado, a paciência demandada, as dúvidas relatadas, bem como o feedback mútuo e a vontade de atingir resultados satisfatórios formaram um conjunto de elementos que nos proporcionaram aprendizados que ultrapassam a disciplina, e até mesmo o curso, impactando, de maneira significativa, nossas visões de mundo, nossas relações e, acima de tudo, nossa esperança em dias melhores.

\section{Notas}

1. Sistema Integrado de Gestão de Atividades Acadêmicas (https://sigaa.ufpb.br/ sigaa/public/home.jsf).

2. Zoom Video Communications, Inc. (https://zoom.us).

3. O conceito de metodologias ativas é apresentado durante a descrição dos procedimentos metodológicos.

4. Tema 1: Multimodality and multiliteracies in the EFL classroom; Tema 2: Remote learning and teaching in the EFL classroom; Tema 3: Intersectionality in the EFL classroom (gender, race, ethnicity, class, age, spirituality, body diversity and sexuality).

5. O questionário intitulado Ensino Remoto e Metodologias Ativas em Tempos de Pandemia foi aplicado por meio do Google Forms, onde consta um Termo de Consentimento Livre e Esclarecido (TCLE), como proteção ética adicional ao disposto, para este tipo de pesquisa (Art. $1^{\circ}$. Parágrafo único. VII), na Resolução CNS no 510 de 07 de abril de 2016, publicada no DOU no 98 de 24 de maio de 2016, que regulamenta pesquisas em Ciências Humanas e Sociais (BRASIL, 2016). Questionário disponível em: https://docs.google.com/forms/ d/1dfYe4XawO3vi9K2vMDZircH-wQJJ38U4aAH5nB_9-vw/prefill. Acesso em: 09 mar. 2021.

6. Metodologias ativas são estratégias de ensino-aprendizagem que "dão ênfase ao papel protagonista do aluno, ao seu envolvimento direto, participativo e reflexivo em todas as etapas do processo, experimentando, desenhando, criando, com orientação do professor" (MORAN, 2018, p. 41).

7. Compartilho o texto que tenho incluído nos planos de curso das minhas disciplinas durante o ensino remoto: ATENÇÃO: A utilização, durante as aulas realizadas na plataforma Zoom, de registro de tela (printscreen) ou qualquer outro tipo de gravação de som e/ou imagem por meio de celular e/ou outro equipamento somente poderá ocorrer com autorização expressa do professor da disciplina e dos/as alunos/as presentes na aula para cada situação específica. As aulas, bem como todo e qualquer material de apoio produzido para a disciplina, não podem ser divulgadas e/ou reproduzidas sem prévia autorização, sob pena de violação da 
Constituição Federal (1988) no que tange a inviolabilidade da imagem da pessoa, bem como da Lei $n^{\circ} 9.610 / 98$, que trata dos direitos autorais.

8. Apesar de não ser objetivo deste estudo, devo esclarecer, rapidamente, que o ensino on-line é entendido como aquele que acontece, como o próprio nome implica, completamente por meio da internet, tendo ou não auxílio para alunos/as por meio de tutoria/monitoria, sendo as aulas ao vivo e/ou gravadas e acompanhadas de material instrucional. Ensino a distância, por sua vez, é uma modalidade bem mais complexa, por meio da qual aulas ao vivo e/ou gravadas são disponibilizadas para alunos/as e acompanhadas de material desenvolvido por um time pedagógico para fim e público específicos, tendo, de maneira diferenciadora de outras modalidades, também momentos de aulas presenciais nos polos estabelecidos em algumas cidades e, necessariamente, auxílio de tutores/monitores juntos ao/à professor/a da disciplina.

9. No original: "temporary shift of instructional delivery to an alternate delivery mode due to crisis circumstances" (HODGES et al., 2020, p. 6).

10. No original: "professional development programming for any personnel involved in the instructional mission of colleges and universities" (HODGES et al., 2020, p. 11).

11. No original: "my main desire has been to make them conceive, and, if possible, reproduce sympathetically in their imagination, the mental life of their pupil as the sort of active unity which he himself feels it to be" (JAMES, 1899, p. iv).

12. No questionário aplicado, todas as perguntas que solicitavam avaliações por parte dos/as alunos/as foram elaboradas para oferecer opções de notas que vão de 1 (extremo negativo) a 5 (extremo positivo).

13. Os estudos identitários, em perspectiva descolonial e interseccional, representam meu principal nicho de pesquisa, tanto na graduação quanto na pós-graduação, marcando, de maneira consciente e socialmente responsável, também minha prática docente (cf. PARAQUETT; BEZERRA, 2021).

14. Os componentes de uma pedagogia dos multiletramentos (experiência, conceituação, análise e aplicação), mencionados neste parágrafo, são propostos e descritos por Cope e Kalantzis (2015, p. 4, minha tradução).

\section{Referências}

AKOTIRENE, Carla. Interseccionalidade. São Paulo: Sueli Carneiro; Pólen, 2019.

ANJOS-SANTOS, Lucas. O(s) papel(eis) do gênero digital fórum de discussão educacional na educação inicial de professores de língua inglesa. Acta Scientiarum. Language and Culture, v. 36, n. 2, p. 159-169, 2014. DOI: https://doi.org/10.4025/ actascilangcult.v36i2.21074.

BEZERRA, Fábio. Multiletramentos na escola: formação e práticas docentes na contemporaneidade. In: PEREIRA, Regina Celi; PEDROSA, Juliene; FERRAZ, Mônica (orgs.). Letramentos em cena: teorias e evidências. João Pessoa: Ideia, 2019. p. 79-103.

BEZERRA, Fábio. Relato de um projeto de multiletramentos na licenciatura de língua inglesa: da prática situada à prática transformada. Travessias Interativas, v. 16, n. 2, p. 68-85, 2018.

BIONDO, Fabiana. Construir conhecimentos linguísticos em fórum online: uma prática colaborativa. Veredas - Revista de Estudos Linguísticos, v. 21, n. 1, p. 40-59, 2017. DOI: https://doi.org/10.34019/1982-2243.2017.v21.28180.

BLAKE, Robert. Bimodal CMC: the glue of language learning at a distance. CALICO Journal,v.22, n. 3, p. 497-511,2005. DOI:https://doi.org/10.1558/cj.v22i3.497-511. 
BRASIL. Conselho Nacional de Saúde. Resolução no 510, de 07 de abril de 2016. Dispõe sobre as normas aplicáveis a pesquisas em Ciências Humanas e Sociais. Diário Oficial [da] República Federativa do Brasil, Brasília, DF, 24 maio 2016. Disponível em: http://conselho.saude.gov.br/resolucoes/2016/Reso510.pdf. Acesso em: 24 mar. 2021.

CASSANY, Daniel. En_línea: leer y escribir en la red. Barcelona: Anagrama, 2012.

CHAPELLE, Carol. English language learning and technology. Amsterdã: John Benjamins Publishing, 2003.

COLLINS, Patricia Hill; BILGE, Sirma. Intersectionality. Cambridge, Malden: Polity Press, 2016.

COPE, Bill; KALANTZIS, Mary. The things you do to know: an introduction to the pedagogy of multiliteracies. In: COPE, Bill; KALANTZIS, Mary (orgs.). A pedagogy of multiliteracies: learning by design. Hampshire, Nova York: Palgrave Macmillan, 2015. p. 1-36.

CULLEN, Richard. Teaching grammar as a liberating force. ELT Journal, v. 62, n. 3, p. 221-230, jul., 2008. DOI: https://doi.org/10.1093/elt/ccm042.

DACOLTIVO, Fernanda; CASTELA, Greice. Contribuições de uma formação continuada para a produção de texto com auxílio das TICS nas aulas de língua espanhola. SOLETRAS, n. 35, p. 121-144, jan./jun., 2018. DOI: https://doi. org/10.12957/soletras.2018.31855.

DEWEY, John. Experience and education. Nova York: Simon \& Schuster, 1938.

GIDDENS, Anthony. Mundo em descontrole: o que a globalização está fazendo de nós. Tradução de Maria Luiza X. de A. Barros. Rio de Janeiro: Record, 2000.

GIMENEZ, Telma; RAMOS, Samantha. Planejamento e implementação de curso online como atividade de estágio curricular na área de inglês. Ilha do Desterro, n. 66, p. 101-131, jan./jun., 2014. DOI: https://doi.org/10.5007/21758026.2014n66p101.

GRABE, William; STOLLER, Fredricka. Content-based instruction: research foundations. In: SNOW, Marguerite; BRINTON, Donna (orgs.) The contentbased classroom: perspectives on integrating language and content. Nova York: Longman, 1997. p. 5-21.

HAMPEL, Regine; STICKLER, Ursula. The use of videoconferencing to support multimodal interaction in an online classroom. ReCALL, v. 24, n. 2, p. 116-137, 2012. DOI: https://doi.org/10.1017/S095834401200002X.

HARASIM, Linda. Learning theory and online technologies. Nova York: Routledge, 2012.

HEBERLE, Viviane. Multimodal literacy for teenage EFL students. Cadernos de Letras UFRJ, n. 27, p. 101-116, dez., 2010.

HODGES, Charles; MOORE, Stephanie; LOCKEE, Barb; TRUST, Torrey; BOND, Aaron. The difference between emergency remote teaching and online learning. EDUCAUSE Review. 2020. Disponível em: https:/er.educause.edu/ articles/2020/3/the-difference-between-emergency-remote-teaching-andonline-learning. Acesso em: 05 set. 2020.

JAMES, William. Talks to teachers on psychology: and to students on some of life's ideals. Nova York: Henry Holt \& Co., 1899.

JEWITT, Carey. Multimodality and literacy in school classrooms. Review of Research in Education, v. 32, n. 1, p. 241-267, 2008. DOI: https://doi. org/10.3102/0091732X07310586. 
KALANTZIS, Mary; COPE, Bill. Repertoire of practice. Works \& Days. 2021. Disponível em: https://newlearningonline.com/learning-by-design/glossary/ repertoire-of-practice. Acesso em: 09 mar. 2021.

LARSEN-FREEMAN, Diane. Techniques and principles in language teaching. Oxford: Oxford University Press, 2000.

LEANDRO, Diêgo; WEISSHEIMER, Janaina. Percepções e usos de tecnologias digitais no ensino de inglês como L2 no NucLiIsF em Natal-RN. Olhares \& Trilhas, v. 21, n. 2, p. 186-203, jul., 2019. DOI: https://doi.org/10.14393/OT2019v21.n.2.42989.

MADEIRA, Fábio. O sistema de crenças do aprendiz brasileiro de inglês: fatores que influenciam na construção de crenças. Trabalhos em Linguística Aplicada, v. 47, n. 1, p. 119-129, 2008. DOI: https://doi.org/10.1590/S0103-18132008000100007.

MARTINS, Rodrigo. A revolta das letras. Carta Capital, São Paulo, ano 19, n. 1055, 22 maio 2019.

MAYRINK, Mônica; ALBUQUERQUE-COSTA, Heloísa. Ensino presencial e virtual em sintonia na formação em línguas estrangeiras. The ESPecialist: Descrição, Ensino e Aprendizagem, v. 38, n. 1, 2017. DOI: https://doi.org/10.23925/23187115.2017v38ila10.

MORAN, José. Metodologias ativas para uma aprendizagem mais profunda. In: BACICH, Lilian; MORAN, José (orgs.). Metodologias ativas para uma educação inovadora: uma abordagem teórico-prática. Porto Alegre: Penso, 2018. p. 35-76.

MORAN, José. Metodologias ativas. Entrevista concedida a João Mattar. YouTube. 2016. Disponível em: https://www.youtube.com/watch?v=9m-wf2qHSOo. Acesso em: 15 out. 2020.

NUNAN, David. Teaching grammar in context. ELT Journal, v. 52, n. 2, p. 101-109, abr., 1998. DOI: https://doi.org/10.1093/elt/52.2.101.

OFUGI, Mariana; FIGUEREDO, Carla. Desenvolvendo a autonomia do aprendiz de inglês como L2/LE com o auxílio da técnica da sala de aula invertida: um estudo de caso. Linguagem \& Ensino, v. 20, n. 2, p. 55-80, 2017. DOI: https://doi. org/10.15210/rle.v20i2.15235.

OMOTADE, Awodun; BABALOLA, Joseph. Pedagogical repertoire of a model language teacher. International Journal for Innovation Education and Research, $\mathrm{v}$. 3, n. 5, p. 82-90, 2015. DOI: https://doi.org/10.31686/ijier.vol3.iss5.362.

PARAQUETT, Marcia; BEZERRA, Fábio. Epistemologias transviadas da Linguística Aplicada na (desen)formação de professore(a)s de línguas estrangeiras. In: MUSSI, Marcos (org.) E-Book I CONELA (título a definir). São Paulo: Pimenta Cultural, 2021. [no prelo].

PEREIRA, Rogéria. Vamos juntos para...: webquests como temática para a mediação cultural no ensino de alemão como língua estrangeira (ALE). EntreLínguas, v. 4, n. 1, p. 114-132, 2018. DOI: https://doi.org/10.29051/rel.v4.n1.2018.11177.

PIRES, Daniel; MICHELS, Paula. Internet and cultural awareness: understanding memes: co-constructing knowledge on internet culture. In: GIL, Gloria; PIRES, Daniel; MICHELS, Paula (orgs.). Doing interculturality in the English classroom: a series of intercultural activities designed for the English as an additional language classroom. Florianópolis: UFSC, 2017. p. 19-24.

REIS, Susana. Ensino de produção oral em língua inglesa por meio de podcast: relatando uma experiência com alunos do ensino fundamental. Veredas Revista de Estudos Linguísticos, v. 21, n. 1, p. 180-201, 2017. DOI: https://doi. org/10.34019/1982-2243.2017.v21.28210. 
RICHARDS, Jack; RODGERS, Theodore. Approaches and methods in language teaching. Cambridge: Cambridge University Press, 2001.

RODRIGUES, Jeanne; MUENCHOW, Nicole; RIBAS, Fernanda. A utilização de softwares para o ensino de inglês como L2: o Edilim como ferramenta para promover a aprendizagem na sala de aula invertida. Veredas - Revista de Estudos Linguísticos, v. 21, n. 1, p. 21-39, 2017. DOI: https://doi.org/10.34019/19822243.2017.v21.28211.

ROJO, Roxane. Pedagogia dos multiletramentos: diversidade cultural e de linguagens na escola. In: ROJO, Roxane; MOURA, Eduardo (orgs.). Multiletramentos na escola. São Paulo: Parábola Editorial, 2012. p. 11-31.

ROYCE, Terry. Multimodal communicative competence in second language contexts. In: ROYCE, Terry; BOWCHER, Wendy (orgs.). New directions in the analysis of multimodal discourse. Mahwah: Lawrence Erlbaum, 2007. p. 361-403.

SABOTA, Barbra; ALMEIDA FILHO, José Carlos. Análise do potencial da mediação tecnológica para o enriquecimento da competência teórica de professores de línguas. Acta Scientiarum. Language and Culture, v. 39, n. 4, p. 369-380, 2017. DOI: https://doi.org/10.4025/actascilangcult.v39i4.31594.

SANTIAGO, Silviano. Uma literatura nos trópicos: ensaios sobre dependência cultural. 2. ed. Rio de Janeiro: Rocco, 2000.

SANTOS, Milton. Por uma outra globalização: do pensamento único à consciência universal. Rio de Janeiro: Record, 2000.

SILVA, Ana; MARIANO, Lorena; FINARDI, Kyria. As novas tecnologias no ensinoaprendizado de L2: refletindo a partir de olhares de professores. LínguaTec, v. 3, n. 6, p. 71-87, 2018. DOI: https://doi.org/10.35819/linguatec.v3.n2.a3290.

STRYKER, Stephen; LEAVER, Betty (orgs.). Content-based instruction in foreign language education: models and methods. Washington: Georgetown University Press, 1997.

THOMAS, Michael; REINDERS, Hayo; WARSCHAUER Mark. Contemporary computer-assisted language learning. Londres: Bloomsbury, 2014.

TUMOLO, Celso. Histórias digitais como recurso para ensino/aprendizagem de inglês como língua estrangeira. Revista Estudos Anglo-Americanos, n. 43, p. 101117, 2015.

TUMOLO, Celso. Recursos digitais e aprendizagem de inglês como língua estrangeira. Ilha do Desterro, n. 66, p. 203-238, 2014. DOI: https://doi.org/10.5007/21758026.2014n66p203.

UFPB - Universidade Federal da Paraíba. CONSEPE - Conselho de Ensino, Pesquisa e Extensão. Resolução $n^{\circ}$ 19/2020, de 06 de agosto de 2020. Dispõe sobre a regulamentação de oferta de componentes curriculares para a graduação em um Período Suplementar, considerando o isolamento social decorrente da pandemia da Doença causada pelo Coronavírus 2019 (Covid-19), com início em 08 de setembro e término em 16 de dezembro de 2020. João Pessoa: CONSEPE, 2020. Disponível em: https://sig-arq.ufpb.br/arquivos/202001124041712354262a 1e817966170/Resp19.20.pdf. Acesso em: 09 mar. 2021.

VIEIRA JUNIOR, Itamar. Torto arado. Lisboa: LeYa, 2018. 